\title{
Antiapoptotic Effect of Ajuga bracteosa Leaves on Hepatic Dysfunction in Alloxan Induced Diabetic Chicks
}

\author{
R. Bisht ${ }^{1}$, D. Kumar ${ }^{1} *$ \\ ${ }^{1}$ Dept. of Zoology, S. V. Govt. P. G. College, Lohaghat -262524, Champawat, Kumaun University, Nainital, Uttarakhand
} (INDIA)

Corresponding author: oxidation01@gmail.com

Available online at: www.isroset.org

Received: 24/Apr/2019, Accepted: 29/Apr/ 2019, Online: 30/Apr/2019

\begin{abstract}
The present study was carried out to assess the antiapoptotic effect of Ajuga bracteosa leaves on the hepatic dysfunction in alloxan induced diabetic chicks. Hydroalcoholic extract of Ajuga bracteosa leaves was prepared by standard method as prescribed earlier and apply for monitoring the liver enzymes including Alkaline phosphatase (ALP), Aspartate amino transferase (AST - SGOT) and Alanine amino transferase (ALT - SGPT) in experimental chicks, including diabetic control and diabetic treated with the hydroalcoholic extract of Ajuga bracteosa leaves at the rate of $100 \mathrm{gm} / \mathrm{Kg}$ body weight and normal control chicks fed with water ad libitum. Present study reveals a significant $(\mathrm{p}<0.05)$ decline in the level of these enzymes in the chicks treated with hydroalcoholic extract of Ajuga bracteosa leaves up to the control level as compared to chicks of diabetic control group. Therefore, administration of hydroalcoholic extract of Ajuga bracteosa leaves in diabetic chicks significantly ameliorate the enzymological parameters for the assessment of hepatic dysfunction in diabetic chicks, which showed the potent antiapoptotic effect of Ajuga bracteosa leaves extract on hepatic dysfunction in alloxan induced diabetic chicks.
\end{abstract}

Keywords: Antiapoptotic, Ajuga bracteosa, Hepatic, Alloxan, Diabetes, ALP, AST - SGOT, ALT - SGPT.

\section{INTRODUCTION}

Diabetes mellitus (DM) is recognized as the most common metabolic and endocrine disorder worldwide. It is a metabolic disease characterized by hyperglycemia and glycosuria due to absolute or relative lack of insulin [1]. Diabetes mellitus is defined by the world health organization (WHO), on the basis of laboratory findings as a fasting venous plasma glucose concentration greater than $7.8 \mathrm{mmol} / \mathrm{l}(200 \mathrm{mg} / \mathrm{dl})$ two hours after a carbohydrate meal or two hours after an oral ingestion of the equivalent of $75 \mathrm{~g}$ glucose, even if the fasting concentration is normal [2]. The chronic hyperglycemia of diabetes associated with long term damage, dysfunction and failure of various organs especially the eyes, kidneys, liver, nerves, heart and blood vessels.

Numerous studies have identified that hyperglycemia may lead to oxidative stress and glycation reactions. Over time, the initial glycation products undergo intramolecular rearrangements and oxidation reactions (glycoxidation) and ultimately transform into stable so-called advanced glycation end-products (AGEs). AGE-modification of proteins can alter or limit their functional or structural properties, which ultimately can lead to tissue damage as seen in diabetes. ALP is also used for the assessment of the liver function. It reaches extremely high levels in biliary obstruction. The altered ALP activity may reflect an increased hepatic insulin resistance or oxidative stress [3].

Liver disease is a type of damage to liver cells or is the disease of liver. Symptoms of liver dysfunction include both physical and symptoms related to the digestive problems, blood sugar problems, immune disorders, abnormal absorption of fats and metabolism problems. The most sensitive and widely used liver blood enzymes are - Alkaline phosphatase (ALP), Aspartate amino transferase (AST - SGOT), Alanine amino transferase (ALT - SGPT). These enzymes are normally contained within the liver cells. 
AST and ALT are sensitive indicators of liver damage from different types of disease. If the liver is injured, the liver cells spill the enzymes into blood, raising the enzyme levels in the blood and signaling the liver damage. Serum glutamate pyruvate transaminase (SGPT), now called Alanine aminotransferase (ALT), is a liver enzyme that is vital for energy production. It is present in different tissues such as the liver, skeletal muscles and heart, but is found with the highest concentration in the liver. When the liver is damaged, SGPT leaks out of the cells and into your blood.

ALP is also used for the assessment of the liver function. It reaches extremely high levels in biliary obstruction. The altered ALP activity may reflect an increased hepatic insulin resistance or oxidative stress [3]. Alkaline phosphatase (ALP) is an enzyme in the cells lining the biliary ducts of the liver. ALP levels in plasma rise with large bile duct obstruction, intrahepatic cholestasis or infiltrative diseases of the liver.

Ajuga bracteosa is a perennial hairy herb, belongs to family Lamiaceae. It is distributed in subtropical and temperate regions from Kashmir to Bhutan, Pakistan, Afghanistan, China, Malaysia, western Himalayas, plains of Punjab and upper Gangetic plains of India at an altitude of 1300m [4]. In ayurveda it is commonly called 'Nilkanthi' (sanskrit) while in Kumaun region of Uttarakhand it is called as 'Ratpatiya'. Many compounds like gamma-sitosterol, beta-sitosterol, triacontanyl docosanoate and tetracosanoic acid have been isolated from its arial part [5]. Other constituents like phenolic components, bitter components, arabinose, cerotic acid, palmitic acid along with glucosidic constituents, D-glucoside and anthocynidin-glucosides also have been found [6].

A decoction of the leaves of the herb is used in the traditional medicine for a number of diseases including diabetes, hypertension, fever, malaria and stomach pain [7]. This plant also had been proved for its ability on lipoxigenase inhibition, antipyretic activity, cholineesterase inhibition, antispasmodic action and antifungal activity [8]. For antimalarial properties, the ethanolic leaves extract of $A$. bracteosa demonstrated a dose-dependent chemo-suppression during early and in established infections, along with significant $(\mathrm{p}<0.05)$ repository activity [9].

The aim of the present study was to assess the antiapoptotic effect of Ajuga bracteosa leaves on hepatic dys-function in alloxan induced diabetic chicks by accessing the liver enzymes activity including ALP, SGOT and SGPT.

\section{METHODOLOGY}

\section{Extract preparation:}

The plants were collected locally, the leaves were shed dried and coarsely powdered. 500 gm powder of shade dried leaves of the plant were mixed with hydroalcoholic solvent containing $80 \%$ of water and $20 \%$ of alcohol, hot extraction of this mixture was carried out by Soxhlet Apparatus. The extract thus obtained was further freeze dried before use.

\section{Animals:}

Eighteen healthy domestic chicks - Croiler chabra (Gallus gallus domesticus), approximately 2-3 weeks old weighing $100 \pm$ $20 \mathrm{gm}$ of either sex, were selected for the study. Selected all chicks were maintained and acclimatized according to the laboratory conditions of the animal house in the department. The animals were housed in battery cages at existing room temperature and relative humidity. They were offered commercial food (Starter, Grower and Finisher) purchased from the market (Godrej Company) and tap water ad libitum. Animal studies had the approval of the Institutional Animal Ethics Committee (IAEC) by the Department of Pharmaceutical Science, Bhimtal (Kumaun University, Nainital) and the member secretary, CPCSEA, Ministry of Environment, Forest and Climate Change, Government of India. Animals were randomized into three groups ( $\mathrm{A}, \mathrm{B}$ and $\mathrm{C}$ ) comprising six chicks in each.

\section{Induction of Diabetes:}

Diabetes was induced in the chicks by administering Alloxan intraperitoneally. Freshly prepared Alloxan monohydrate (12 $\mathrm{mg} / 100 \mathrm{gm}$ body weight) was injected for 7 days daily in Group A and B chicks. The diabetes was confirmed in chicks by estimating blood glucose level by using Glucose test kit (ARKRAY Healthcare Pvt. Ltd., Surat, India). The animals which were confirmed to be diabetic having blood glucose level $\geq 250 \mathrm{mg} / \mathrm{dL}$ was used for the study.

\section{Experimental Design:}

The chicks were divided into three groups (A, B and C) randomly, each containing six chicks. After one week diabetes was induced in chicks of group A and B with alloxan $(120 \mathrm{mg} / \mathrm{kg}$ body weight, i.p.). Chicks with a blood glucose level $\geq 250$ $\mathrm{mg} / \mathrm{dL}$ were considered to be diabetic. Group A chicks served as Diabetic Control while Group B served as diabetic chicks 
treated with hydroalcoholic extract of Ajuga bracteosa leaves (100 mg/kg, orally, 30 days daily); Group C chicks were served as Normal control.

The treatment was given in fasting state and food was provided after dosing the animals.

\section{Blood sample collection:}

At the end of the experiment all the chicks were starved overnight and sacrificed by light ether anesthesia in morning hours. Blood samples were collected through cardiac puncture and serum was prepared by centrifugation; and serum was immediately stored for further analysis of hepatic dysfunction.

\section{Liver enzyme assessment:}

Serum samples were assessed to estimate the levels of liver enzymes including ALP, SGOT and SGPT; and were determined colorimetrically.

\section{Statistical Analysis:}

Values are expressed as mean \pm S.E. Statistical significance was determined by one way analysis of variance (ANOVA) followed by student's " $t$ test". $P<0.05$ were considered statistically significant.

\section{RESULTS AND DISCUSSION}

Medicinal plants have been used since ancient times with an increase in the development of drugs from natural sources and plants in recent few years. Pharmacologists and researchers have keen interest in identifying remedies from plants and natural sources [10]. Diabetes mellitus is a pandemic of $21^{\text {st }}$ century and is growing faster day by day, affecting many people on the globe. Traditional and natural plant based remedies are still the first choice of people in the developing countries, because of their minimum or no adverse side effects [11]. In the present study the antiapoptotic effect of hydroalcoholic extract of Ajuga bracteosa leaves on hepatic dysfunction in alloxan induced diabetic chicks was assessed.

The results of present study a significant elevation in the activities of ALP, SGOT and SGPT enzymes were observed in diabetic control chicks of Group A as compared with the corresponding Group B diabetic chicks treated with hydroalcoholic extract of Ajuga bracteosa leaves. The administration of hydroalcoholic extract of leaves of Ajuga bracteosa in chicks of group B significantly ameliorate the disturbance occurred in the activities of these liver enzymes up to control level. (Table 1, Figure 1).

Table 1: Effect of hydroalcoholic extract of Ajuga bracteosa leaves on liver Enzymes in Alloxan induced diabetic chicks:

\begin{tabular}{|clllc}
\hline Group & \multicolumn{1}{c}{ Treatment } & ALP (IU/L) & SGOT (IU/L) & SGPT(IU/L) \\
A & Diabetic control & $11.4 \pm 0.75^{*}$ & $23.3 \pm 0.67 *$ & $17.5 \pm 0.53 *$ \\
B & Diabetic + Ajuga bracteosa & $8.5 \pm 0.69^{* *}$ & $19.1 \pm 0.67 * *$ & $11.8 \pm 0.98 * *$ \\
C & Normal control & $7.4 \pm 0.40$ & $16.2 \pm 0.64$ & $10.2 \pm 0.58$ \\
\hline
\end{tabular}

Results are expressed as mean \pm S.E. *Significantly different $(\mathrm{p}<0.05)$ when compared with Group B treated with hydroalcoholic extract of Ajuga bracteosa leaves. **Significantly different $(\mathrm{p}<0.05)$ when compared with normal control chicks treated with saline. Analysis of variance (ANOVA) were significant among all these groups for ALP (10.7, p<0.05), SGOT (28.85, p<0.05) and SGPT (24.64, p<0.05).

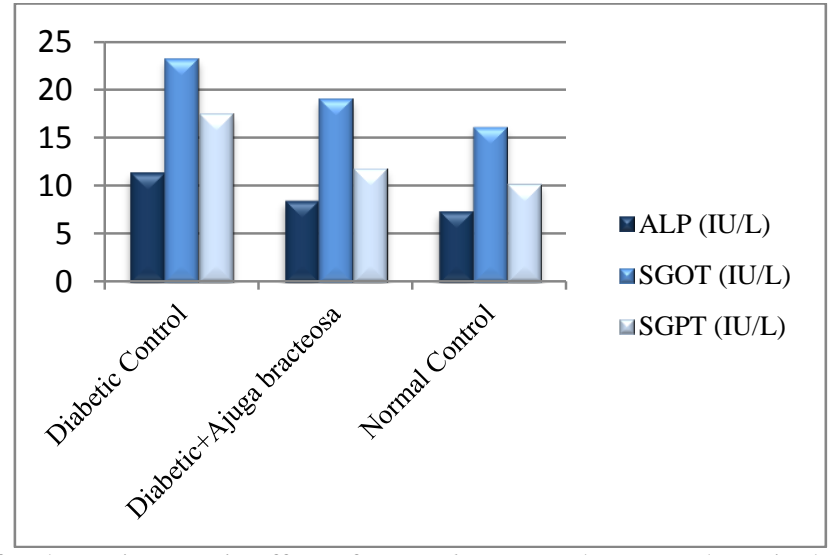

Figure 1: Graphical representation for the antiapoptotic effect of Ajuga bracteosa leaves on hepatic dysfunction in alloxan induced diabetic chicks. 
Diabetes mellitus causes disturbance in the uptake of glucose as well as glucose metabolism. DM is associated with the progressive metabolic derangement, worsening glycaemic control and morphological changes in the kidney, liver, retina, pancreas and other organs $[12,13]$. Liver plays an important role in the maintenance of blood glucose levels by regulating its metabolism [14]. The hepatic serum enzymes are valuable tool in clinical diagnosis and it provides information on the effect and nature of pathological damage to tissue [15].

AST and ALT were enzyme that catalyzes the transfer of amino acid aspartate and alanine respectively to group ketoglutaric acid. ALT was mainly found in the liver but AST was found in various tissues such as the heart, skeletal muscles, kidney, brain and liver $[16,17]$. ALT is present in cytosol of hepatosit, meanwhile AST was present in cytosol and mitochondria of hepatosit $[16,18]$.

Furthermore, ALP, SGOT and SGPT are biomarkers which are often used to assess the integrity of the plasma membrane and tissues after being exposed to certain pharmacological agents [19]. The increase in the activities of serum AST and ALT indicated that diabetes may have induced hepatic dysfunction. This may be attributed to hyperglycemia which promotes reactive oxygen species (ROS) accumulation, accelerates cellular damage and significantly contributes to the diabetic complications development and progression [20].

In this research, alloxan was used for the induction of diabetes in chicks which results in the elevation of ALP, SGOT and SGPT enzyme of liver in blood. Alloxan produced free radicals [21]. Free radicals could disrupt the DNA, Protein, lipid and membrane cell resulting cell damage [22, 23]. The hydroalcoholic extract of Ajuga bracteosa leaves reduced the level of ALP, SGOT and SGPT. This means that the extract was thought to be able to regenerate hepatosit. The suspected mechanism of this effect was caused by antioxidant effect of Ajuga bracteosa. Ajuga bracteosa was found to contain compounds of the class diterpenoids and withasteroids, which are a group of 28 naturally occurring steroidal lactones built on an intact or rearranged ergostane framework. Withasteroids exhibit a number of biological activities such as anti-microbial, anti-tumor, antiinflammatory, hepatoprotective, immunomodulatory, cytotoxic, antisecticidal and insect-antifeedant properties [24, 25, 26, 27]. The antioxidants can inhibit cell damage because this agent can scavenge free radical [28].

Results of present study is consistent with the report that initial and most important indicators in assessing liver injury are elevation in the levels of ALP, SGOT and SGPT indicate [29, 30, 31] and an increase in the level of these enzymes in diabetes may be as a result of leaking out of these enzymes from the compromised tissue into the blood stream [32, 33]. Our results indicate possible ameliorative and liver protective role played by hydroalcoholic extract of Ajuga bracteosa in alloxan induced diabetes in chicks.

\section{CONCLUSION AND FUTURE SCOPE}

Diabetes mellitus and its complications are associated with free radical mediated cellular injury and lipid metabolism. Present study showed antiapoptotic effect of Ajuga bracteosa on hepatic dysfunction in alloxan induced diabetic chicks; by lowering the enzymes of liver including ALP, SGOT and SGPT in blood in Ajuga bracteosa treated diabetic chicks. It supports the possibility of using the Ajuga bracteosa extract in diabetes management and its complications. Further more scientific studies are needed in this for its future medicinal scope.

\section{REFERENCES}

[1]. C.N. Aguwa, "Diabetes mellitus. In: Therapeutic basis of climate pharmacy in the tropics", Optimal publishers, Enugu, Nigeria. pp.1 - 453, 1994.

[2]. H.U. Nwanjo, E.A. Nwokoro, "Anti-diabetic and biochemical effects of aqueous extract of V. amygdalina leaf in normoglycaemic and diabetic rats”, J. Innov. Life Sci, 7:6 - 10, 2004

[3]. G.N. Levinthal, A.S. Tavili, "Liver disease and diabetes mellitus", Clin Diabetes, 17:2, 1999.

[4]. C.P. Khare, "Indian Medicinal Plants - An Illustrated Dictionary”, 1st Indian Reprint Springer (India) Pvt. Ltd., New Delhi, India, $28,2007$.

[5]. P.R. Rastogi, B.N. Mehrotra, Central Drug Research. Institute of Sciences communication, New Delhi,1:19, 1960-1966.

[6]. R.N. Chopra, S.L. Nayar, Chopra C, Glossary Indian Medicinal Plants, PID: New Delhi, 10, 1956.

[7]. K.M. Nadkarni, Indian Materia Medica, Popular prakashan private Ltd., Mumbai, 58, 1976.

[8]. Z.H. Israili, B. Lyoussi, “Ethnopharmacology of the plants of genus Ajuga”, Pak. J. Pharm. Sci. 22(4): 425-462, 2009.

[9]. S. Chandel, U. Bagai, "Antiplasmodial activity of Ajuga bracteosa against Plasmodium berghei infected BALB/c mice”, Indian J. Med. Res. 131: 440-444, 2010.

[10]. L.C. Tapsell, I. Hemphill, L. Cobiac, C.S. Patch, D.R. Sullivan, M. Fenech, S. Roodenrys, J.B. Keogh, P.M. Clifton, P.G. Williams, V.A. Fazio, K.E. Inge, "Health benifits of herbs and species: the past, the present, the future", Med J 185 (4suppl): S4-S24, 2006.

[11]. R.N. Okigbo, E.C. Mmeka, “An appraisal of phytomedicine in Africa”, Sci Technol J, 6:83-94, 2006. 
[12]. M.N. Cook, C.J. Girman, P.P. Stein, C.M. Alexander, R.R. Holman, "Glycaemic control continues to deteriorate after sulfonylureas are added to metformin among patients with type 2 diabetes”, Diabetes Care, 28:995-1000, 2005.

[13]. $\quad$ L. Cristina, L. Roberto, D.P. Stefano, " $\beta$-cell failure in type 2 diabetes mellitus", Curr Diab Rep, 8:179-184, 2008.

[14]. M.A. Nagy, S.A. Mohamed, “Antidiabetic effect of Cloem Droserifolia (Cloemaceae)”, American Journal of Biochemistry, 4(4):68-75, 2014.

[15]. P. Daisy, K. Saipriya, "Biochemical analysis of Cassia fistula aqueous extract and Phytochemically synthesized gold nanoparticles as hypoglycemic treatment for diabetes mellitus", Int J Nanomedicine, 7:1189-1202, 2012.

[16]. H.R. Rosen, E.B. Keefe, "Evaluation of abnormal liver enzymes, use of liver tests and the serology of viral hepatitis: liver disease, diagnosis and management", New York; Churchill livingstone publishers; 1 st ed., p. 24-35, 2000.

[17]. S.F. Friedman, P. Martin, J.S. Munoz, "Laboratory evaluation of the patient with liver disease. Hepatology, a textbook of liver disease", Philedelphia, Saunders publication, 1:661-709, 2003.

[18]. S. Sherlock, “Assessment of liver function disease of liver and biliary system”, London, Blackwell science ltd, 10 th $\mathbf{e d . ,}$ p. 17-32, 1997.

[19]. N.R. Ratod, I. Raghuveer, H.R. Chitme, R. Chandra, "Free radical scavenging activity of Calotropis gigantea on streptozotocin induced diabetic rats", Indian J Pharm Sci, 71(6):615-621, 2009.

[20]. C.V. Diogo, J.M. Suski, M. Lebiedzinska, "Cardiac mitochondrial dysfunction during hyperglycemia-the role of oxidative stress and p66Shc signalling”, Int J Biochem Cell Biol, 45:114-22, 2013.

[21]. K. Asayama, F. Nyfeler, D. English, S.J. Pilkis, I.M. Burr, "Alloxan-induced free radical production in isolated cells selective effect on islet cells", Diabetes, 33:1006-12, 1984.

[22]. I.S. Young, J.V. Woodside, “Antioxidants in health and disease”, J Clin Pathol, 54:176-86, 2001.

[23]. V. Lobo, A. Patil, A. Phatak, N. Chandra, "Free radicals, antioxidants and functional foods: Impact on human health", Pharmacogn Rev, 4:118-26, 2010.

[24]. N. Riaz, S.A. Nawaz, N. Mukhtar, A. Malik, N. Afza, S. Ali, S. Ullah, P. Muhammad, M.I. Choudhary, Chemistry \& Biodiversity, 4: 72, 2007.

[25]. E. Glotter, Natural Product Reports, 8: 415, 1991.

[26]. R.D. Budhiraga, S. Sudhir, Journal of Scientific Indian Research, 46: 488, 1987.

[27]. A.B. Ray, M. Gupta, Progress Chemical Organic Natural Products, 63: 1, 1994.

[28]. B. Halliwell, "How to characterize an antioxidant-an update", Biochem Soc Symp, 61:73-101, 1995.

[29]. J.M. Crawford, C. Iacobuzio-Donahue, "Liver and biliary tract", In: V. Kumar, A.K. Abbas, N. Fausto, J.C. Aster, Eds. Robbins and Cotran Pathologic Basis of Disease. 8th ed. Philadelphia,Pennsylvania, USA, Saunders, pp. 833-90, 2009.

[30]. D.L. Longo, A.S. Fauci, D.L. Kasper, S.L. Hauser, J.L. Jameson, J. Loscalzo, Harrison's Principles of Internal Medicine. New York, USA, McGraw-Hill, Vol 2, 18th ed., 2011.

[31]. M. Nannipieri, C. Gonzales, S. Baldi, R. Posadas, K. Williams, S.M. Haffner, et al., "Liver enzymes, the metabolic syndrome, and incident diabetes: The Mexico City diabetes study", Diabetes Care, 28:1757-62, 2005.

[32]. N.M. Concepcion, M.M. Pilar, A. Martin, J. Jimenez, U.M. Pilar, "Free radical scavenger and antihepatoxic activity of Rosmarinustomentous" Planta Medica, 59:312-314, 1993.

[33]. R.U. Ukpanukpong, J.O. Ajani, Wa. Omang, M.A. Adejorin, M.U. Eteng, E.U. Eyong, "Antidiabetic and antilipidemic effect of Khaya senegalensis Ethanolic bark extract in alloxan induced diabetic Wistar rats”, 7(8): 291-307, 2018. 